\title{
STATUS CONDITIONALITY OF CULTURAL SPENDING AND TOURIST MOTIVATION IN SERBIAN SOCIETY ${ }^{1}$
}

\author{
(example of analysis of traveling abroad)
}

DOI: http://dx.doi.org/10.18509/GBP.2015.66

UDC: 338.486.2:005(497.115)

\author{
Associate professor PH.D. Ljubica Rajković \\ Assistant professor PH.D. Vesna Miletić- Stepanović \\ ${ }^{1}$ Faculty of geography, University of Belgrade
}

\begin{abstract}
This paper presents a primary research of traveling abroad by citizens of Serbia as a dominant form of cultural spending, or more specifically, a primary research of motivation in tourism. The paper offers a special way of analysis of the relation between cultural spending through travelling abroad and stratification and social categories in Serbian society. In Serbian society, as a dividing line within the practice of cultural spending among the population who travels abroad, there appear to be three dimensions: status, urban locality and education, that is to say, it has been observed that Serbian members of the public who have high status, high education and urban locality tend to travel abroad. At the centre of this paper is a survey designed to investigate the manner in which the people of Serbia spend their leisure time together with the analysis of their opinions and beliefs concerning travel, aimed at determining to what extent travel abroad is a cultural practice and a form of cultural spending by Serbian people as well as the impact it has on the structure of the society. The field survey was conducted in the period March - May 2014 by the first year students of Tourismology of the Faculty of Geography in Belgrade, which formed a part of their compulsory practical work within Sociology of Tourism. The poll was conducted in traveling agencies in Belgrade and other cities in Central Serbia, according to the students' individual choice and accessibility. The sample comprises 613 polled participants from urban and rural settlements.
\end{abstract}

Keywords: Serbia, status, habitus, cultural spending, practice of traveling abroad

\section{INTRODUCTION}

This paper investigates culture as practice - practice of traveling abroad. This paper takes culture to be "everyday occurrence which we get to know through its everyday manifestation" [5]. To the best of our knowledge, no research has been made so far in Serbia dealing with traveling abroad by the population, as a form of cultural spending. This investigation aims to present data concerning traveling abroad and considers to which extent cultural practices reproduce class divisions (class differences).

\footnotetext{
${ }^{1}$ The article is part of the project of the new challenges of social integration in Serbia - the challenges and the stakeholders, document number 179035, whose implementation the Ministry of Science and Technological Development of Republic of Serbia
} 


\section{THEORETICAL APPROACH}

The theoretical framework underpinning the investigation is practice theory which connects cultural activity spending with social status. The paper rests on theoretical posits by Pierre Bourdieu who introduces cultural dimension in sociological study of stratification. This renowned theorist holds that culture and cultural spending contribute to the reproduction of class system in contemporary societies, and that between economical positions (classes) and life styles (status groups) there exists invariant unchangeable relation - classes emerge as status groups whose culturally stratified tastes and goods legitimize the system of economic domination. The theoretical model shows the relation between objective conditions of living by classes on the one hand, and life styles on the other. Great emphasis is placed on the influence of social structure on shaping of cultural practices. Pierre Bourdieu claims that there exists homology correspondence between social and cultural stratification. Habitus is what stands between social and cultural stratification (Bourdieu, 2004). In his practice theory, Pierre Bourdieu starts from the assumption that life styles are systemic production of habituses. Positions and habituses are in dialectic relation (Bourdieu, 2004: 134). Objective living conditions combine with the position within social structure and produce habitus. Habitus is a system of patterns which generate practices both in parts and in the entirety of the system of perception and evaluation patterns (tastes). Habitus, central to the practice theory, acts as an intermediary between living conditions and lifestyles. Both social and cultural practice are made possible through habitus, defined as the capability for producing practices (Bourdieu, 2004: 132), a system of relatively enduring dispositions in keeping with objective conditions in which they occur. Dispositions, which comprise habitus, form a foundation for generating practices. Habitus is acquired through experience and produces socially competent behaviors through habit and routine (Bourdieu, 2004: 132). Habitus produces cultural practices and actions which make up style of life - lifestyle. At the foundation of life is taste, that is, tendency and striving to adopt... practices (Bourdieu, 2004: 135). He determines lifestyles through objective situation of possessing capital which is manifested as habitus, while habitus is defined as disposition (Bourdieu, 2004: 134). Cultural capital comprises symbolic capabilities, tastes and goods for generating symbolic profit - social status or prestige. Specifically, interest-oriented behaviour occurs not only in economic but in cultural practices as well: people use their resources to maximize their profit in cultural sphere [2]. Cultural capital is distributed unequally between classes, which reproduces social structure. Social order and social norms are reproduced through cultural mechanisms and processes of symbolic violence. Symbolic violence means imposing symbolical systems and meanings - culture- on groups and classes in such a manner that they do not perceive them as forceful but rather as legitimate, inherent or natural. The fact that social groups perceive this process as legitimate serves to obscure actual power relations. These two organizational principles determine both the structure and the changes of cultural spending, and broadly, the whole universe of lifestyles. The main division is specified according to the structure of capital (Bourdieu, 2004: 139).

\section{RESEARCH HYPOTHESES}

In accordance with the dialectics of status and habitus, traveling abroad is conditional upon the social status of a respondent. Traveling abroad is part of the middle and higher 
class habitus and constitutes an element of exclusive cultural practice. Culture and social structure are mutually conditional. Social positions of respondents, formal education and occupations strongly affect their cultural needs - cultural conditionality of social practices. Satisfying the need for traveling abroad is class conditional and strengthens the relation between economic classes and cultural spending, with cultural spending, in turn, being a fundamental driver of inequality, class polarization and preservation of existing social structure. Socially conditioned patterns can be recognized within cultural spending: cultural practices and class are connected and there can be drawn a parallel between the cultural field in which cultural practices occur and social field in which actors occupy social positions. More specifically, activities relating to cultural spending reflect features of social stratification. We made the assumption that there is a hierarchy of cultural spending activities: they occur more frequently among middle and high class population, and less frequently among the representatives of the subordinate social groups. Within "unjust social division of competences" [5], dominant, governing or "high" social groups have taken the most favorable positions in terms of possessing material wealth, power and status, that is, they have at their disposal advantageous circumstances (life opportunities) for satisfying cultural needs - namely, traveling abroad. This class is privileged within the overall social structure which is manifested as privileged material position, that is, this class is free from worry for everyday existence, and therefore able to satisfy the needs relating to travel - the need for "growth", or "meta-needs" as a value of a "being". They are in the position to have the opportunity to learn something new. Naturally, there are also other choices from the conglomerate of a distinctive lifestyle: attitudes and opinions considering what is "for us" and "not for us" [5]. Therefore traveling abroad using the services of tourist operators is significant for satisfying the needs of cultural spending, as well as other types of needs.

\section{Research method}

Empirical research using survey technique was applied, with a questionnaire as an instrument. The hypotheses underpinning the investigation were examined through experiential scientific evidence obtained from a survey conducted in Serbian society. The field survey was completed in the period March-May 2013, by the students of Tourismology at the Faculty of Geography of the Belgrade University, within their obligatory practical work for Sociology of Tourism course. The survey was conducted in tourist agencies in Belgrade and cities of central Serbia, with the members of the public who happened to be at the tourist facilities at the time of the poll. The sources of data are primary, that is, original, obtained from respondents found in natural, field work conditions, obtained by combination of a survey and an interview. The paper is based on the analysis and interpretation of quantitative and qualitative data. For all variables frequency was calculated and necessary cross referencing was drawn. In addition to the discussion of individual variables, correlation between them was also determined correlation coefficient.

\section{Sample}

The sample is stratified, random, comprising 613 respondents in all. The strata were determined on the basis of the territorial distribution of the population, by age, gender, school attainment and occupation. The sample comprises individuals who: a) happened to be at the tourist agency over the course of a specified time period, and b) were willing to answer the questions asked of them. 


\section{Variables}

INDEPENDANT: social position of travelers abroad

DEPENDANT: characteristics of travel abroad depending on what traveling abroad means to individuals, namely, what is the need being satisfied - the choice of destination and the motivation for tourist travel, relation between age and travel practice, educational attainment and travel practice, occupation and travel practice, gender differences and traveling abroad.

\section{RESULTS AND DISCUSSION}

The first question to be dealt with is to what extent traveling abroad, as a specific form of cultural spending, is connected to the status structure of Serbian society - namely, with social class. The activities are divided into the following categories:

1. investigating the relation between cultural spending (through traveling abroad) and stratification divisions and social categories in Serbian society.

2. investigating the significance of traveling abroad for satisfying cultural needs and cultural practices.

\section{Sociological variable: Class}

The first phase of analysis of data on traveling abroad, as a specific form of cultural practice, was forming groups by material position: the index of material position of respondents sums up eight components present in their households: income of respondent and the overall household income, ownership of immovable property (house, apartment, business facilities), savings, holiday destinations and ownership of cars. The indices were formed on the basis of objective data weighted by significance of particular dimensions, while the index of material position itself is an interval scale with four levels: high, middle, low and sub-status (underclass). Households were divided into categories by the number of "points" assigned on the basis of objective indicators. Here we shall attempt to illustrate how satisfying cultural needs is conditional upon sociological variables. As shown in, $15 \%$ of all respondents hold high social position. Towards the other end of the scale, accounting for $17.8 \%$, there are "low" social groups, characterized by culture of lack, shortage and scarcity: lack of knowledge, social recognition and possibility of choice [5]; due to their disadvantaged position in a system of inequality and lack of financial resources they are not in a position to choose cultural spending practice. The position between the highest and the lowest is occupied by the respondents of middle social class. As for the middle class, it has been assumed that it ceased to exist in any observable sense in terms of material wealth, namely, their material status has been severely compromised, especially in terms of current income, however, other elements constituting social position such as cultural and social capital, better working conditions, value orientation, have remained intact. Over the period of this investigation, almost every second respondent, $46 \%$ belonged to the middle class. Sub-status groups (under-classes) occupy a specific position. They comprise students, unemployed young respondents without regular source of income, who took their role in the practice of cultural spending for traveling abroad thanks to their parents who paid for travel - school excursions (accounting for 13.4\%), together with informal relations and communication networks among inner family members, relatives and close friends living and working abroad, accounting for $17.8 \%$. 
Data show that sample of travelers abroad, assumed to be to a certain extent representative for all those who travel through traveling agencies, mostly comprises middle and high classes, almost $2 / 3$ of all respondents $(61 \%)$, which can be explained by the conditionality of cultural spending upon the position an individual occupies in a social hierarchy, or, more specifically, that class position affects cultural spending and satisfying cultural needs. Sub-status groups, students and the unemployed, accounting for every fifth respondent $21.2 \%$ (130) run counter to this tendency. By connecting social position of respondents and their role in the production of cultural practice through traveling abroad, it can be seen that when traveling abroad one in seven had a connection with the diaspora, that is, $15.2 \%$ (93 out of 613), from which, $44.1 \%$ from lower classes, $45.2 \%$ from the middle and $10.7 \%$ from the higher class.

\section{Reasons for traveling abroad in satisfying cultural needs and cultural practices}

The next question which we attempted to answer is to what extent the practice of traveling by the respondents was satisfied by cultural spending and how does it relate to satisfying other needs? On the basis of responses to the question put to the respondents what traveling abroad meant to them and what need they tried to satisfy, cultural participation was quoted by one of two travelers abroad using the services of travel agencies, namely, 54\%. Cultural participation was divided into: a) cultural reception (spending) unfolding through the selection of tourist destination serving cognitive needs

(learning about new cultures, exotic places, historical monuments, religious reasons) $32.1 \%$ and b) cultural reception for satisfying recreational needs (being with friends, fun, pleasure) $-21.9 \%$, amounting to $54 \%$ in all for cultural participation. Familial reasons for traveling were quoted by $17.8 \%$ (visiting close relatives and friends abroad). The relation between travel costs and travel preferences was investigation through the analysis of prices: cheap, favorable prices, low prices of travel arrangements were quoted as a deciding reason by one in six respondents, that is, $15.5 \%$. Traveling abroad through traveling agencies for business or market research was quoted as reason for traveling by $8.3 \%$ while other reasons, such as health, shopping and similar, accounted for $4.4 \%$.

\section{Demographic variables of respondents}

As claimed before by other authors [5], demographic features of respondents are an important determinant in terms of satisfying cultural needs, namely, most weight carry: educational attainment, age, sex and place of residence (rural/urban). Demographic correlations presented by respondents are also suited to the purpose of investigation because they are observable in all responedents and their investigation can produce sociological correlates found cultural spending actors.

\section{Place of residence of respondents and traveling practice}

Central to the investigation of the cultural spending activity was the issue whether belonging to a certain age group carries more weight than the factor of the location or culture in which we have been socialized and in which we live? To what extent does the place where we live affect decisions relating to traveling abroad? Where are the boundaries of the culture to which we belong? The hypothesis underpinning the analysis of place of residence of respondents is the assumption that urbanity is an important factor of cultural spending practice as well as a resource for affirming one's own superiority over others. Therefore urbanity becomes a mark for a multitude of various, highly valued 
values: refinement, modern world view, tolerance and similar, as opposed to primitivism and uncivilized behavior, namely, urban-dwelling is associated with refinement and civilization and glorified as opposed to rural-dwelling. In this respect, the respondents resided in four locations - four strata: 1. Belgrade, 2. medium sized cities, 3. villages closer to a bigger city, up to $10 \mathrm{~km}$ away and 4 . villages over $10 \mathrm{~km}$ away from a city. Random sampling was applied within all of the four strata. In the overall example, urbanity accounted for as much as $90 \%$ (552). First, about the City of Belgrade. The respondents mostly point out their love of travel and how often they travel. Among travelers abroad. The phenomenon of "belgradization", combining the concentration of money, power, high education and lucrative occupation is prominent among the respondents. The extent to which respondents bring up urban-dwelling mostly depends on some objectively measurable features, such as education, class and occupation. The inclusion of the variable urbanity, namely, urban identity, considerably widens the concept and sheds more light on the profile of travel consumers - high status, high culture, as measured by a formal indicator of years of education as well as lucrative occupations: politicians, entrepreneurs, experts. First to be dealt with is the connection between urbanity and class, by examining the variables place of residence and status. Data show that dominant social classes express urbanity as much as $95.6 \%$, middle class $89.0 \%$, low $79.3 \%$ while those from the sub-status are an exception with $92.2 \%$ - correlation coefficient $c=0.392$. For city-dwellers, urbanity means openness to the cultural spending activity expressed through traveling abroad.

\section{Age and traveling practice}

Young people travel more often than others. More specifically, the practice of traveling abroad is commensurate with the age of respondents. This fact was indirectly confirmed in this segment of research through the investigation of the connection between the practice of traveling and the age of respondents. It was demonstrated that younger population (18-30) and those of the optimum age (31-50) traveled abroad more often than the rest, to be precise, $82.2 \%$. As expected, age affects the activities of cultural spending, manifested by traveling abroad, in two opposing directions: positively for age groups 18 30 and 31-50 and negatively for the elderly, especially those over 65, 3.6\%. Data shows that there is a large gap between age groups 18-30 and 31-50 and the respondents of older age.

\section{Educational level and traveling practice}

In addition to status and age, education is of utmost importance as a factor of discrimination related to cultural activity spending. In most cases correlation with education is positive, namely, the higher educational attainment, the higher probability of positive attitude towards traveling abroad practice, and vice versa, which, in turn, presupposes high cultural capital and better position in the stratification ladder. There is rising correlation between high school attainment and traveling demonstrating that cultural spending activity strongly depends on urbanity of respondents (90\%), status $(61 \%)$ and high education $(60.4 \%)$. 


\section{Professional structure and traveling practice}

Relation between occupation of respondents and traveling practice is of considerable importance for proving the starting hypothesis that occupation is closely related to openness to traveling abroad as a cultural form of spending. Thus it is possible to discern a clear difference in preferences by occupational groups in relation to traveling abroad: dominating are highly lucrative occupations: owners, management and experts, $49.9 \%$. Also pronounced is the negative attitude held by agricultural and blue collar occupations (1.0\% and $4.7 \%$ respectively (see also, [3]; [2]). Traveling abroad by users of services provided by tourist agencies is proportionate to education and occupation and prevalent among respondents with university education, with high cultural capital and socioeconomic status as measured by occupation and job. Active manifestation of cultural spending practice - traveling abroad is significant for affirming class belonging, which is in keeping with the theoretical assumption of this investigation which rests upon Bourdieu's claim about strong connection between culture and social inequality. As expected, the bond between the practice of traveling, educational attainment and occupation runs in the same direction as the one between traveling and urbanity, confirming the social status held by actors of cultural spending.

\section{CONCLUSION}

In spite of the limitations of this work, namely, the attempt to draw conclusions about structural differentiation in Serbian society solely on the basis of traveling abroad using the services of traveling agencies on the part of members of the public, the findings of the investigation support the hypothesis that process of differentiation does indeed occur in the area of satisfying cultural needs. The findings show that traveling abroad is conditional upon the social position of the actors. Data show that the sample of travelers abroad, assumed to be representative of overall users of travel agency services, comprises mostly individuals from the middle and high class, that is, almost $2 / 3$ of all respondents (61\%), supporting the claim that exclusive cultural practice is a feature of middle and high echelons. This finding supports the claim that cultural spending is indeed conditional upon the position of an individual in the social hierarchy, that is, that class affects cultural spending and satisfying cultural needs. This does not hold true for sub-status groups: students and the unemployed, accounting for one in five respondents; this fact can be explained by social capital: relations and communication networks among close family, relatives and close friends in the country and abroad. Social position, as sociological variable, determines choices relating to satisfying cultural needs. Cultural spending practice in the form of traveling abroad through travel agencies remains a privilege of higher social echelons, reflecting characteristics of social stratification and the bond between cultural spending activities and class. Traveling abroad through tourist agencies as a cultural form in a semi-periphery society such as Serbia functions as a mark of distinction accessible only to higher classes. In Serbian society, the medial axis dividing practice of cultural spending among the population traveling abroad, exhibits the following dimensions: status, urbanity and education. The observed tendency of Serbian citizens with high socio-economic status, cultural capital and urban residence to travel abroad places this type of tourism in the category of luxury cultural practice. 


\section{SELECTED LITERATURE:}

[1] Burdje, Pjer (2004). „Habitus i prostor stilova života“, In: Kultura, No.109/112, Belgrade, pps. 131-170

[2] Cvetičanin, Predrag (2007). Kulturne potrebe, navike $i$ ukus građana Srbije $i$ Makedonije. Niš: Odbor za građansku inicijativu.

[3] Košničar, Sofija (1999): „Kulturne potrebe i ponašanja stanovnika Srbije (I, III)“, In: Zbornik Matice srpske za društvene nauke, No. 104-105, pps. 89-108, Novi Sad. [4] Republic Statistical Office, Census of the RS for 2002. Belgrade: RSO.

[5] Spasić, Ivana (2013): Kultura na delu. Društvena transformacija Srbije iz burdijeovske perspektive, Belgrade: Edition: REČ. 